\title{
MEMories of Professor ARISTEo RENZONI
}

\section{Stefania Ancora}

\section{Department of Physical Sciences, Earth and Environment, University of Siena, Italy}

\begin{abstract}
Here were reported Memories of Professor Aristeo Renzoni, University of Siena. Among the first Professors of Ecology in Italy and internationally recognized scientist. In almost 60 years of research he published over 250 scientific papers. The main ecological and environmental topics of his research were the histology of reproductive structures of bivalves, the histology of the pineal gland in birds, the accumulation of mercury in large pelagic predators of Mediterranean Sea, the contamination of organochlorine compounds in bird eggs, the lead shot pollution from hunters activities in wetlands.
\end{abstract}

Key words: Aristeo Renzoni, pineal gland in birds, mercury in Mediterranean Sea, organochlorines in birds eggs, lead shot pollution in wetlands.

I first met Professor Renzoni in the early 90s, when he was Full Professor of Ecology at the Faculty of Mathematics, Physics and Natural Sciences of University of Siena. At that time, he he was at the height of his academic and scientific career, in his more senior period of the activity, with a number of research achievements, while I was just a student taking his courses. A few years passed and I started working with him. Although he was nearing the end of his career and his health was no longer at its best, it was enough to establish a relationship of esteem and affection.

It's not easy to summarize his almost 60 years of research which yielded over 250 scientific papers. His childhood in Bettolle and the surrounding countryside, with a grandfather and uncle who were farmers and hunters, was certainly of fundamental importance for his research in veterinary, medicine, biology, zoology and, later, in ecology and environmental sciences He always paid close attention to the surrounding territory and nature, observing everything and noticing details and small changes in what his eyes looked upon, whether it was the edge of wood, or a cultivated field or the banks of a river. I remember that up to his final years in the Department of Environmental Sciences he continued to jot down the date of the arrival of the swifts and other birds (as seen from the window of his office overlooking the botanical gardens).

On field trips, whatever their purpose, he would stop to point out group of European bee-eaters, the flight of a heron or a common buzzard on some perch. The same was the true on longer trips expeditions whether by train or cars - the latter being a bit more dangerous. And if he saw a shepherd with his flock, he would get

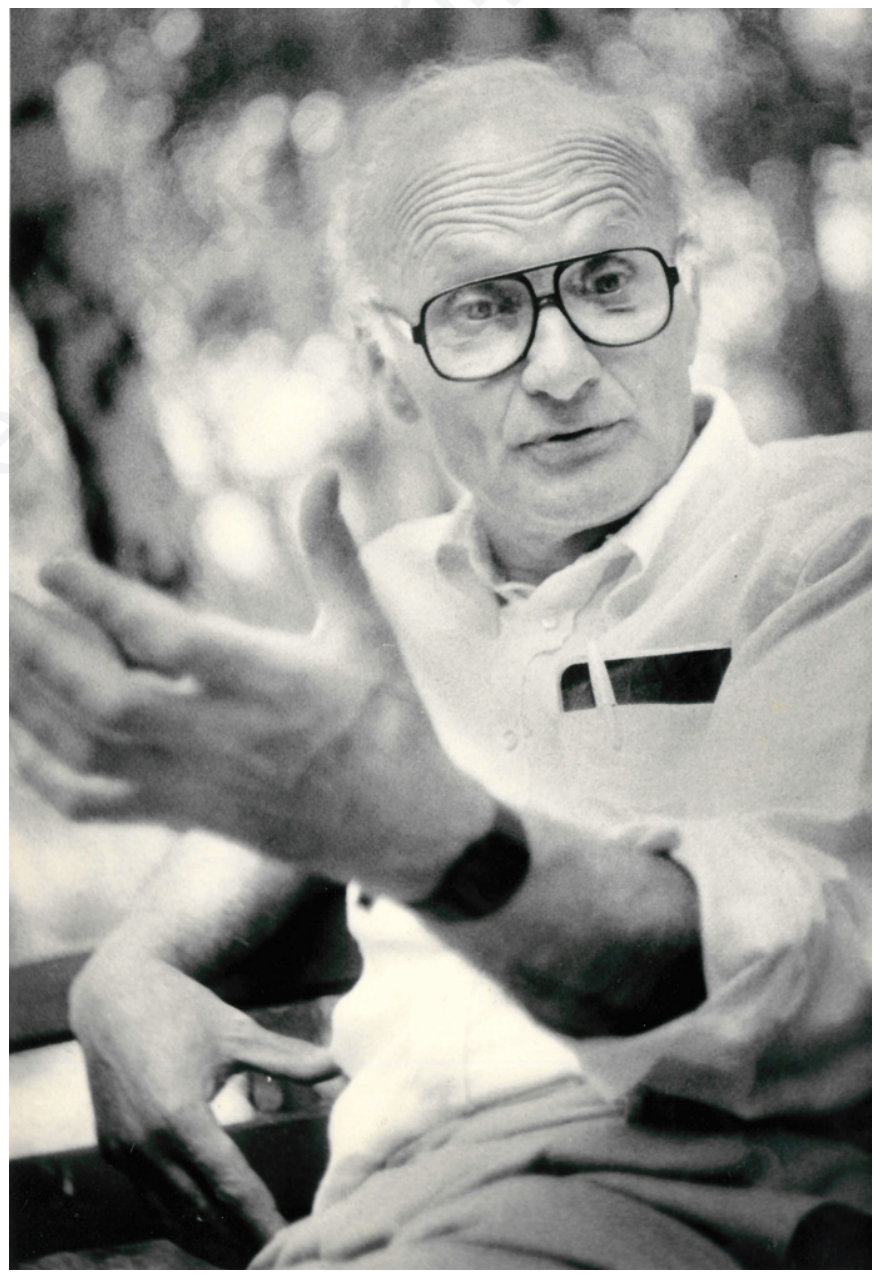

Aristeo Renzoni. 
out of the car to go and talk to him. His innate interest in such matters as well as his skills and his life experience led to a degree in Veterinary Sciences at the University of Perugia in 1951 and his becoming Assistente Straordinario at the Institute of Normal Anatomy of Domestic Animals there.

After a grant from the Italian Ministry of Education to do research at the School of Veterinary Medicine in Hannover (Germany), he worked at the Anthon Dohrn Zoological Station in Naples where he did research in anatomy and histology. In 1960 he returned to Siena as Professor Omodeo's Assistant in what was then the Institute of Biology and General Histology, a part of the School of Medicine and Surgery. Here he did research on karyology, first in earthworms and then in mammals and birds, which he was very skilled at raising.

His work on histology and the comparative anatomy led to one a year of research with Bill Quay at the University of California at Berkeley on the pineal gland of birds, in particular nocturnal raptors, and on the importance of the photoperiodism for the reproductive and migratory behaviour of birds.

Back in Siena where the Faculty of Mathematics, Physics, and Natural Sciences finally came into being in 1965, he soon became Aggregate Professor in Hydrobiology and Fisheries. In 1973 his first paper on effects of detergents and petroleum and its derivatives on the development of marine bivalves and the effects of various toxic substances on quail reproduction were published. Mercury pollution soon became a major interest. He studied the metal accumulation in fishes from Mount Amiata rivers and from along the coasts of the Tyrrhenian Sea, in the eggs of marine birds and in the large pelagic predators of the Mediterranean Sea such as the Bluefin tuna, as well as in the hair of fishermen and dentists. Such studies were initially performed thanks to a technical collaboration of the Institute of Mineralogy and subsequently, through the acquisition of an atomic absorption spectrophotometer and the creation of laboratories specialized in the chemical analysis of all find of all kinks of environmental matrices. He once told me that his interest in mercury pollution and its biological effects came, al least in part because, because while on the beach with his family near the Rosignano Solvay factory (releasing wastewater containing mercury) a neighbour said "Don't let your children swim in that water!". A few years later he became interested in the organochlorine compounds contamination that was causing serious problems to the reproductive success of birds of prey.

I often wondered how he always managed to take up what would turn out to be among the most important environmental issues in the years to follow. Along with his intuition and his scientific background, Professor Renzoni was very inspired by his reading. He read a great deal, and his desk was always surrounded by piles of scientific magazines, Science and Nature, but also magazines for hunters and fishermen and newspapers, keeping himself more than up to dated locally and globally.
By the beginning of the 80s, Ecology had taken root in Italy and the research unit in Siena was among the best established. In that period Professor Renzoni became a founder of the Italian Society of Ecology along with professor Moroni (Parma), professor Marchetti (Milan), professor Genovese (Messina) and professor Faranda (Genova), each with their own particular speciality.

He was involved in national and international research projects including those on oceanography supported by the National Research Council and on the Mediterranean Action Plan to study the impact of contaminants on the Mediterranean Sea and human heath, jointly supported by Food and Agriculture Organization and the World Health Organisation (United Nations Environment Programme). He represented the University of Siena in the National Research Council and in the Tuscan Regional Park of Maremma and that of Migliarino San Rossore Massaciuccoli where he was president for its first 5 years.

Professor Renzoni, together with Professor Sarfatti, founded the Department of Environmental Biology and under his guidance the ecological and environmental research and teaching at the University of Siena achieved international recognition. That was in part due to his desire not to be confined to Siena and Tuscany and to his organizational skill in promoting international exchanges. He gave as many students as possible a chance to grow and to bring their energy to numerous research projects. He represented the University of Siena in a Consortium between European and Russian Universities (the Association for Promotion of International Cooperation with Scientists of New Independent States of the Former Soviet Union), he coordinated the Socrates Erasmus Exchanges Programme and dedicated himself to the Doctoral School. However the most important international achievement was the creation of the yearly Summer School at Certosa di Pontignano, where Italian and international students gathered to hear and discuss with some of the most famous scientists on environmental pollution and human health. He managed to maintain a dense network of contacts, writing countless letters, making a great many phone calls and sending many faxes....but I think it was his manner of being that inspired sympathy.

He often said "What a great thing it is to earn your living while having fun!".

Towards the end of his life he still found energy and will to undertake research on lead pollution in wetlands caused by the shot from hunters' cartridges and a research to which various young researchers and I collaborated.

When walking had become harder, instead of entering his office, he used to work at the small table in the main corridor of the Department. This was his new strategy, a way of being able to observe what was happening, to keep up contacts, and at least exchange greetings with all of us who had grown humanly and scientifically under his tutelage. 